\title{
Inference Claims as Assertions
}

\section{MatThew W. MCKeON}

\author{
Michigan State University \\ South Kedzie Hall \\ East Lansing, MI 48824-1032 \\ mckeonm@msu.edu
}

\begin{abstract}
When a speaker states an argument in arguing - in its core sense-for the conclusion, the speaker asserts, as opposed to merely implies or implicates, the associated inference claim to the effect that the conclusion follows from the premises. In defense of this, I argue that how an inference claim is conveyed when stating an argument is constrained by constitutive and normative conditions for core cases of the speech of arguing for a conclusion. The speech act of assertion better reflects such conditions than does implication, conversational implicature, or conventional implicature.
\end{abstract}

Résumé: Lorsqu'un locuteur avance des raisons pour appuyer une conclusion, dans le sens fondamental d'argument, il affirme, et non simplement implique ou insinue, l'inférence associée que la conclusion découle des prémisses. Pour défendre ceci, je soutiens que la façon dont une affirmation d'inférence est exprimée lorsqu'on avance un argument est limitée par des conditions constitutives et normatives pour les cas fondamentaux du discours d'argumentation. L'acte de parole de l'assertion reflète mieux ces conditions que l'implication, l'implicature conversationnelle ou l'implicature conventionnelle.

Keywords: arguments, arguing for a conclusion, assertion, inference claims, implicature

\section{Introduction}

In arguing for a conclusion by stating an argument for it one conveys an inference claim to the effect that the conclusion follows from the premises. How is the inference claim conveyed by stating the argument? Is it merely implied, implicated in some way, or asserted? In this paper, I develop a response in two steps. First, I clarify what I take to be arguing for a conclusion in its core sense in a way that highlights the significance of inference claims. Second, based on this clarification, I argue that by stating an argument 
in arguing for its conclusion one asserts the associated inference claim as opposed to merely implying or implicating it.

More specifically, I first argue in favor of the following three claims. (i) One isn't arguing for a conclusion in its core sense unless one believes the associated inference claim. (ii) Arguing for the conclusion in this way doesn't pass normative muster unless the inference claim is true or acceptable. (iii) When so arguing for the conclusion the inference claim that is expressed is a primary point in stating the argument. I then argue that given (i)-(iii) when a speaker $\mathrm{S}$ states an argument in core cases of arguing for its conclusion $S$ asserts the associated inference claim and doesn't merely imply or implicate it.

It has been maintained in the literature that what I am calling inference claims are implied by what statements of arguments express (Hitchcock 2011, p. 214), conveyed as conversational implicatures (Bermejo-Luque 2011a, p. 64) conveyed as conventional implicature (Grice 1989, pp. 25-26), and implicitly asserted when stating arguments (Hitchcock 2011, pp. 191-192). I believe that this paper is the first to justify that they are asserted by appealing to (i)-(iii), which I take to be motivated by the notion of arguing for a conclusion in its core sense. With respect to such core cases of arguing for a conclusion, your statement of an argument does not implicate the corresponding inference claim and what you express only implies it in the trivial sense that what you assert you thereby imply.

I start by clarifying the notion of an argument in its reasongiving sense, distinguishing between such arguments and statements of them. I then introduce the concept of an inference claim, which a speaker S conveys by her statement of an argument in its reason-giving sense. The question arises how $\mathrm{S}$ expresses an inference claim by making such a statement. In response, I first clarify what I take to be core cases of arguing for a conclusion. I then argue that S's statement of an argument counts as arguing for the conclusion in such ways only if $\mathrm{S}$ asserts the associated inference claim in stating the argument. Finally, I conclude. 


\section{Preliminaries: arguments, statements of arguments, and inference claims}

\subsection{Arguments and statement of arguments}

Two senses of "argument" in the informal-logic literature are the formal-logic and argumentation senses. According to the first, an argument is an ordered pair. The first member is the set of premises, the second is the conclusion. An argument in the argumentation sense is a complex speech act in which an arguer presents a thesis to an audience and defends it with premises advanced as reasons for the thesis. Goldman (1994, p. 27) calls the formal logic and argumentation senses of "argument," the abstract and social senses, respectively. Biro and Siegel (2006, p. 92) speak of a similar distinction between arguments as abstract objects and arguments in use. As Goldman suggests, these senses needn't be competing. An argument in the argumentation sense advances the premises of an argument in the formal-logic sense as reasons for the conclusion, i.e., the thesis the arguer aims to defend.

In this paper, both the abstract and social senses of argument are in play. Specifically, I take an argument to be a premiseconclusion complex of propositions. For simplicity of exposition, I'll focus on simple (as opposed to extended) arguments and so at the start take an argument to be an ordered pair of a set of propositions (premises) and a conclusion proposition. Borrowing from Hitchcock (2007, p. 103), I take the reason-giving sense of argument to be an initial conception of argument as a type of discourse in which the arguer expresses a point of view (encapsulated in the conclusion) and offers one or more reasons (the premise(s)) in support of the conclusion. The reason-giving sense of argument is an initial conception of a use of an argument qua premiseconclusion complex of propositions according to which the premises are advanced, collectively, as reasons in support of the conclusion. The reason-giving sense of argument is akin to Goldman's social sense of argument: an argument in the social sense is an argument in the reason-giving sense.

Arguments are used in reason-giving ways to realize a variety of aims such as: (i) to communicate one's reasons for which one accepts the conclusion (Thompson 1967); (ii) to communicate 
hypothetical reasoning (Meiland 1989); and (iii) to persuade an addressee of the truth of the conclusion (Pinto 2001).

(i) A: Where's Beth?

$\mathrm{B}$ : Beth is listening to music on the stereo and so is in the living room.

(ii) A: Where's Beth?

$\mathrm{B}$ : If Beth is listening to music on the stereo and so is in the living room, then she doesn't want to be disturbed.

(iii) A: Beth is not in the house.

$\mathrm{B}$ : She is. She is listening to music on the stereo.

In exchanges (i)-(iii), B's response uses an argument in its reasongiving sense in order to communicate her reason for which she believes the conclusion, to communicate what B takes to follow from a supposition, and to persuade $\mathrm{A}$ of the conclusion, respectively. B's responses state argument $\mathrm{C}^{1}$

Beth is listening to music on the stereo

$\therefore$ Beth is in the living room

By 'state' I mean 'express.' If one asserts something or merely gives voice to it, then one expresses and so states it. To state an argument is to express it. There is a process/product ambiguity with respect to "the statement of an argument." For example, "the statement of C" designates both the speech act of stating argument $\mathrm{C}$ and what is stated. B's statement of C in (i) refers to B's speech act of stating $\mathrm{C}$ and the proposition stated, i.e., Beth is listening to music on the stereo and so is in the living room. In what follows, I'll let the sentential context disambiguate my uses of "statement of an argument."

No statement of an argument is equivalent with the argument that is stated. One commonly acknowledged rationale is that an argument can be stated in different ways (e.g., see Vorobej 2006,

${ }^{1}$ This is to read B's response in (ii) as stating argument $\mathrm{C}$ in the antecedent. 
p. 9). For example, the following two sentences can be used to express one and the same argument: "Not every Republican is rich, so some Republicans won't benefit from the tax cuts"; "some Republicans are not rich; consequently, not every Republican will benefit from the tax cuts." These sentences so used are different statements of one and the same argument.

\subsection{Inference claims}

In contrast to the formal logician's use of arguments in the abstract sense, arguments in the reason-giving sense are typically characterized as arguments (in the abstract sense) used to claim implicitly or otherwise that some propositions support the truth of another. Often, informal-logic texts characterize arguments in their reasongiving sense and associate them with claims to the effect that some propositions support another proposition by virtue of being evidence, grounds, or reasons for its truth (e.g., Kelley, 2014, p. 69; Copi and Cohen 2005, p. 6; and Govier 2010, p. 3).

With respect to the reason-giving sense of argument, Hitchcock remarks that, "[w]hat is crucial to an argument is the claim that the reasons offered collectively support the conclusion" (2007, p. 105). Hitchcock calls such a claim an "inference claim." It is commonly held in the argumentation and informal logic literature that a claim to this effect is essential to an argument in its reasongiving sense. E.g., see Scriven 1976, p. 84; Grennan 1994, p. 187; Groarke 2002, p. 51; Vorobej 2006, pp. 8-9; and Bermejo-Luque 2011 a, p. 90.

We may think that there are two independent roles for "therefore" and its cognates: mere conclusion designator (e.g., Corcoran $1993)^{2}$; and the expression of a relation of support between premises and conclusion (e.g., see Epstein 2002, Hamblin 1970, and Hitchcock 2007, et al). The therefore of informal logic differs from the formal-logic therefore, because informal logic considers arguments in their reason-giving sense. In stating $p$ therefore $q$ in

\footnotetext{
${ }^{2}$ Corcoran (1993, p. xx) emphasizes that an argument in this sense doesn't per se purport to show anything, and so it's misleading to say that the conclusion is based on the argument's premise set or that the premises are given for the conclusion. Corcoran remarks that his subsequent use of " $\therefore$ " to express arguments is best not read as therefore but simply as conclusion.
} 
order to advance $p$ as a reason for $q$ a speaker conveys that $p$ is reason on behalf of $q$ (for textbook explications of this use of therefore see Govier 2010, p. 3 and Fogelin and SinnottArmstrong 2010, p. 51). In this way, the use of a therefore to state an argument in its reason-giving sense is different from its use as mere conclusion-designator in the presentation of an argument in the abstract sense. This suggests that one's statement of an argument is truth evaluable only relative to a reason-giving use of it.

On my view, an inference claim is crucial to an argument in the reason-giving sense in two ways. First, a speaker S uses an argument to advance its premises as reasons that collectively support the conclusion only if $\mathrm{S}$ claims implicitly or otherwise that the conclusion follows - in some sense-from the premises. So, claiming that the conclusion follows from the premises is constitutive of using an argument in a reason-giving way. Second, S's reason-giving use of an argument doesn't pass normative muster unless the associated inference claim is true. If false, then S's attempt to establish the truth of the conclusion by advancing the premises as reasons in support of it is unsuccessful. These two connections between inference claims and reason-giving uses of argument motivate thinking that the truth of an inference claim bears on that of the statement of the corresponding argument. For example, in conversational exchange (ii) above, B's statement of argument $\mathrm{C}$ is intuitively untrue if Beth being in the living room doesn't follow from her listening to music on the stereo.

In sum, the operative notion of argument in this paper is a premise-conclusion complex of propositions that is distinct from any statement of it. The statement of an argument used in a reasongiving way is truth-evaluable and conveys an associated inference claim. In what follows, I'll adopt Hitchcock's (2011) first-step characterization of inference claims according to which an inference claim says, in effect, that the conclusion follows from the premises. $^{3}$

\footnotetext{
${ }^{3}$ Hitchcock (2011) advances an analysis of follows from towards providing an account of the general form of inference claims. My intent here in sticking with this first-step characterization of inference claims is to remain neutral on its theoretical development, which doesn't have a direct bearing on the aims of the paper.
} 
How, exactly, is the inference claim so construed conveyed? For example, when a speaker $\mathrm{S}$ utters, " $p$ so, $q$ " in order to advance $p$ as a reason for the truth of $q$, how is the associated inference claim, $q$ follows from $p$, conveyed by S's statement of the argument? Specifically, does S merely imply, implicate in some way, or assert it? I assume that these alternatives are mutually exclusive. The remainder of the paper is devoted to developing my response.

Towards this end, I consider statements of arguments made in core cases of arguing for their conclusions. I maintain that if a speaker S's statement of an argument counts as a core case of arguing for its conclusion, then S conveys the corresponding inference claim by means of asserting it. In the next section, I clarify the paper's operative sense of arguing for a conclusion in a way that motivates constraints on accounts of how inference claims are conveyed. In section 4, I deploy these constraints to make the case that one asserts the inference claim when stating an argument in arguing for its conclusion as opposed to merely implying or implicating it. Here I remain neutral on the manner inference claims are conveyed when reason-giving arguments are stated by speakers who are not arguing for their conclusions in the sense operative here. So, I only partially answer the question posed one paragraph back.

\section{The complex speech act of arguing for a conclusion}

In order to clarify the paper's operative sense of arguing for a conclusion, I highlight three facets of the connection between inference claims and this complex speech act. First, stating an argument doesn't count as arguing for its conclusion in its core sense unless the arguer believes the associated inference claim. Second, arguing for its conclusion in this way is normatively problematic unless the inference claim is true and the arguer is justified in believing the inference claim. Third, the inference claim conveyed by one's statement of an argument is not informationally and conversationally subordinate to the main content of the statement of the argument. 


\subsection{Inference claims and argumentation}

I take arguing for a proposition to be a form of what van Eemeren and Grootendorst characterize as argumentation.

Argumentation is a verbal, social, and rational activity aimed at convincing a reasonable critic of the acceptability of a standpoint by putting forward a constellation of propositions justifying or refuting the proposition expressed by the standpoint. (2004, p. 1)

Arguing for a proposition, construed along the lines of this notion of argumentation, is a complex speech act (1984, pp. 29-35). That is, arguing for a proposition (pro-argumentation as opposed to contra-argumentation, i.e., arguing against a proposition (1984, p. 9)) is reflected in a variety of argumentative moves that are speech acts such as stating an argument, arguing against a proposed refutation of an argument, and clarifying terminology (van Eemeren and Houtlosser 2003, p. 87; van Eemeren and Grootendorst 2004, p. 52 and 62 , et al).

Drawing on van Eemeren and Grootendorst, I'll consider the speech act of arguing for a conclusion in the context of a critical discussion, which I'll construe simply as a discussion between a protagonist (Pro) and an antagonist (Con) triggered by their desire to resolve their difference of opinion with respect to some claim (the standpoint). ${ }^{4}$ The role of Pro in the discussion is to defend the standpoint; Con's role is to raise doubts about it (2004, pp. 60-61). Their aim is to resolve their difference of opinion. It's realized only when Pro and Con have reached agreement on the acceptability of the standpoint (2004, pp. 57-58).

Suppose Pro argues for the standpoint by stating an argument in its reason-giving sense, i.e., by advancing premises as reasons in support of the standpoint represented by the conclusion. What

\footnotetext{
${ }^{4}$ Van Eemeren and Grootendorst provide a theoretical model of the ontology of a critical discussion (2004, Ch. 3), as well as operative norms (2004, Ch. 8). A starting point for their theorizing is their intuitive characterization of a discussion between participants who aim to resolve a difference of opinion by exchanging arguments and advancing reasoned responses to criticisms (e.g., 1984, pp. 1-2, where critical discussions are referred to as "argumentative discussions"). For an alternative but related account of the speech act of arguing see Bermejo-Luque (2011a, Ch. 3).
} 
makes Pro's speech act of stating an argument count as arguing for the conclusion? Van Eemeren and Grootendorst contend that Pro isn't arguing for the conclusion unless Pro aims to persuade Con of it $(2004$, p. $53 ; 1984,47-49) .{ }^{5}$ In order to highlight a connection between inference claims and arguing for a conclusion, I now motivate another necessary condition.

Following Searle's (1969) way of distinguishing types of speech acts, van Eemeren and Grootendorst advance a number of conditions constitutive of successfully arguing for a conclusion $\mathrm{O}$ by adducing premise-statements $S_{1}, S_{2}, \ldots, S_{n}$ (1984, pp. 39-45). One such success condition is the sincerity condition.

$\mathrm{S}$ believes that the constellation of statements $\mathrm{S}_{1}, \mathrm{~S}_{2}\left(, \ldots, \mathrm{S}_{\mathrm{n}}\right)$ constitutes an acceptable justification of O" (1984, p. 44).

A speaker is not successfully arguing for a conclusion $\mathrm{O}$ by adducing premises unless the speaker believes that the premises constitute an acceptable justification of $\mathrm{O} .{ }^{6}$ Granted that there are other senses of "arguing for a conclusion," I take the sincerity condition to reflect a core sense of arguing for a conclusion by stating an argument. By arguing for a conclusion in this sense, one advances what may be labelled an a persona (from the person) argument, ${ }^{7}$

5 Van Eemeren and Grootendorst approvingly note (1984, p. 36) Searle's remark that "II am simply stating that $\mathrm{p}$ and not attempting to convince you' is acceptable and 'I am arguing that $\mathrm{p}$ and not attempting to convince you' is not" $(1969,66)$. I take Searle's remark to be compatible with acknowledging uses of arguments other than as instruments of persuasion. E.g., to figure out what to believe, to demonstrate that one has worked out an inference claim for a tutor. This turns on the plausible claim that such uses of argument do not constitute acts of arguing for their conclusions. I don't have space to elaborate.

${ }^{6}$ Van Eemeren and Grootendorst worry that the sincerity condition is too speaker-centered and so doesn't reflect the obligations of arguers when they don't believe that the premises they advance justify the conclusion. They think, in effect, that if a respondent $\mathrm{R}$ justifiably takes a speaker $\mathrm{S}$ to be arguing for a conclusion in a critical discussion, then $\mathrm{R}$ is entitled to hold $\mathrm{S}$ responsible for the inference claim even if S doesn't believe the inference claim (1984, p. 42). This puts $\mathrm{S}$ on the hook to defend the inference claim if challenged by $\mathrm{R}$ (note 20 p. 195). As I discuss just below, I take the sincerity condition to enable an intuitive doxastic requirement normative for acts of arguing for a conclusion.

${ }^{7}$ I thank the reviewer for suggesting the notion of a persona argument to clarify the paper's operative sense of arguing for a conclusion. 
which is a type of argument in its reason-giving sense. Such an argument is put forward as the author's own argument for the conclusion. In using a persona argument to argue for its conclusion, a speaker S advances the premises as S's reasons to believe the conclusion. Specifically, the premises of such an argument are among S's reasons for which S accepts the conclusion.

The author of such an argument believes the premises constitute an acceptable justification of its conclusion, and so believes that the conclusion follows from them in some way. This grounds a cognitive connection between inference claims and arguing for a conclusion that I take to be reflected by the sincerity condition. Specifically, arguing for a conclusion in the operative sense here requires that one believe the inference claim associated with the corresponding a persona argument. If you state an argument whose inference claim you do not believe, then you do not state an a persona argument. Accordingly, you aren't arguing for the conclusion in the way that is of concern here. Hereafter, unless specified otherwise, this is the operative notion of arguing for a conclusion, ${ }^{8}$ and a persona argument is the corresponding type of argument.

To summarize, in order for a speaker S's statement of an argument to count as an act of arguing for the conclusion, $\mathrm{S}$ must believe the associated inference claim. This is constitutive of the act of arguing for a conclusion by stating the corresponding argument. This constitutive connection between inference claims and arguing for a conclusion is reflected by Belief.

\footnotetext{
${ }^{8}$ Clearly, this notion of arguing is not idiosyncratic. For example, according to Bermejo-Luque (2011a) a constitutive goal of a speaker S's arguing for a conclusion is to show that a target claim is correct (p. 53), and the corresponding sincerity condition requires, in effect, that $\mathrm{S}$ believes what I refer to as the inference claim (p. 72). Also, Aiken and Talisse (2019, p. 11) take, as a starting point, an argument advanced by a speaker S to be S's attempt not only to make clear what S's reasons are for her conclusion-belief, but also to vindicate or defend what $\mathrm{S}$ believes by showing that her conclusion-belief is well-supported by compelling reasons. I take it that according to these notions, the premises $\mathrm{S}$ advances for the conclusion are among the reasons for which $\mathrm{S}$ believes it. This is the operative sense of arguing here.
} 
(Belief) You express an inference claim by your statement of an argument in arguing for its conclusion only if you believe the inference claim.

If you don't believe the inference claim, your statement of an argument can't count as an act of arguing for the conclusion because, by Belief, you don't express the inference claim. ${ }^{9}$ Accordingly, Belief grounds a pragmatic criterion that S's statement of an argument must satisfy in order to count as a successful act of arguing for the conclusion. Specifically, S must believe the inference claim in order for her statement of the argument to express it.

\subsection{Inference claims and argumentation norms}

On my view, there are argument-centric and speaker-centric normative features of arguing for a conclusion. The argument-centric features are the properties that the argument stated should have in order for the statement of it to realize the aim(s) of the relevant critical discussion. An argument's possession of these properties makes good its use to argue for the conclusion. One of these goodmaking features $\mathrm{F}$ determines that the associated inference claim is good. ${ }^{10}$ An argument's possession of $\mathrm{F}$ is significant, in part, because the statement of the argument advances the aims of the relevant critical discussion only if the associated inference claim is good.

This motivates a speaker-centric normative feature of arguing for a conclusion. S's use of an argument to argue for its conclusion in a critical discussion passes normative muster only if $\mathrm{S}$ is justified in believing that the argument advances the aim(s) of the discussion. Again, an argument advances the aims of critical discussion only if the associated inference claim is good. Therefore, S's use of an argument to argue for its conclusion in a critical

\footnotetext{
${ }^{9}$ Although you could certainly be taken to express one. What it is to "count as an act of arguing for the conclusion" is interestingly ambiguous in this way, just like promising - between whether it is really that or just appears to be and so is taken to be.

${ }^{10}$ I don't take rhetorical features such as being comprehensible to the intended audience and on-topic as such features.
} 
discussion passes normative muster only if $\mathrm{S}$ is justified in believing that the associated inference claim is good.

Clarification of what makes an inference claim good turns on the identification of the corresponding good-making feature $\mathrm{F}$ of arguments. Therefore, different accounts of $\mathrm{F}$ generate different accounts of what makes inference claims good ones. To illustrate, I'll use the Objective Epistemic and Pragma-dialectic approaches to argumentation norms. To be sure, neither approach features inference claims. Nevertheless, I'll borrow from these different approaches to illustrate how the relevant good-making features of arguments underwrite what makes inference claims good.

According to the Objective Epistemic Approach (OEA), the primary aim of the rules of good argumentation is truth and the avoidance of error (Goldman 1994, p. 29). An argument doesn't advance the aim of truth and avoidance of error unless its premises justify the truth of the conclusion, i.e., unless the argument is epistemically sound. An argument is epistemically sound only if the corresponding inference claim is true. Therefore, an argument advances the aim of truth and avoidance of error only if the corresponding inference claim is true. So, the proper use of an argument to argue for its conclusion (i.e., a use that advances the aim of truth and avoidance of error) requires the user to be justified in believing that the inference claim is true (e.g., see Goldman 1994, p. 34, specifically argumentation rule 4c).

According to the Pragma-dialectic Approach (PDA), the primary aim of a critical discussion is rational consensus, i.e., the rational resolution in a critical discussion of a conflict of opinion regarding a standpoint (van Eemeren and Grootendorst 2004, p. 5). An argument doesn't advance the aim of such consensus unless it is reasonable. If an argument is reasonable, then it's both problem valid and intersubjectively valid, i.e., it is relevant to resolving the difference of opinion regarding the standpoint and it's acceptable to both Pro and Con (van Eemeren and Grootendorst 2004, pp. 1617). Therefore, the statement of an argument advances the aim of consensus only if the corresponding inference claim is acceptable to both Pro and Con. So, in order for a discussant's use of an argument to pass normative muster and thereby advance the aim of consensus, she must be justified in believing that the inference 
claim is acceptable to Pro and Con. Accepting the inference claim is manifested in a commitment to defending it in light of criticism and retracting it in case such criticism is unanswerable (van Eemeren and Grootendorst 2004, pp. 54-55).

To summarize, the OEA and PDA inspired proposals for the good making feature of arguments that make inference claims good are epistemic soundness and reasonableness, respectively. These different good-making features of arguments determine different normative qualities of inference claims. According to the OEA-inspired proposal, inference claims aren't good unless they are true. According to the PDA-inspired proposal, they aren't good unless they are acceptable to the involved parties. These different proposals determine different speaker-centric normative features of arguing for a conclusion. According to the OEA-inspired proposal, a speaker S's use of an argument to argue for its conclusion is normatively successful only if $\mathrm{S}$ is justified in believing that the corresponding inference claim is true. According to the PDAinspired proposal, this obtains only if $\mathrm{S}$ is justified in believing that the inference claim is acceptable to all discussants.

That the sincerity condition is constitutive of successfully arguing for a conclusion enables an intuitive, doxastic requirement that is normative for acts of arguing for the conclusion. Specifically, the sincerity condition enables the norm that in order for an act of arguing for the conclusion to pass normative muster the speaker $\mathrm{S}$ must be justified in believing the inference claim. If believing the inference claim isn't necessary to successfully argue for a conclusion by stating an argument for it, why should it be an operative norm that S's believing the inference-claim be justified? What I am pointing to here is that the sincerity condition has a normactivating function by virtue of determining a normative space enabling doxastic norms that guide the speech act of arguing for a conclusion by stating an argument. ${ }^{11}$

In short, a speaker S's statement of an argument doesn't count as a good act of arguing for its conclusion unless the argument that

11 The sincerity condition isn't determinative of which doxastic norms are correct. On my view, the norms enabled by the sincerity condition are motivated by the primary aims of the relevant dialectical context of the speech act. Different accounts of these discursive aims may motivate different norms. 
is stated is good and S's is justified in believing this. An argument is good only if the corresponding inference claim is good, i.e., is true or acceptable. Therefore, S's statement of an argument is a good act of arguing for its conclusion only if (i) the inference claim that is conveyed is true or acceptable, and (ii) $\mathrm{S}$ is justified in believing that the inference claim is true or acceptable.

Intuitively, (1) the statement of an argument made in arguing for its conclusion is true or acceptable only if the argument that is stated is good. As the OEA and PDA inspired proposals illustrate, (2) if the argument that is stated is good, then the associated inference claim is true or acceptable. Value is implied by (1) and (2).

(Value) If the statement of an argument made in arguing for its conclusion is true or acceptable, then so too is the inference claim it conveys.

By the lights of Value, an argument being good (e.g., epistemically sound, reasonable) bears on whether statements of them are true or acceptable. Furthermore, if $\mathrm{S}$ is justified in believing that her statement of an argument is true or acceptable, then Value enables the transference of this justification to S's belief that the inference claim is also true or acceptable. ${ }^{12}$ Given that a statement of an argument doesn't count as a good act of arguing for its conclusion unless (i) and (ii) (just above) obtain, Value underwrites the idea that a speaker's act of arguing for a conclusion by stating an argument is good only if the statement of the argument is true or acceptable. This idea is intuitively plausible.

\subsection{Inference claims and statements of arguments}

Intuitively, when arguing for a conclusion a speaker expresses an inference claim in stating an argument in order to realize a primary aim of arguing for the conclusion. This motivates Primary.

\footnotetext{
${ }^{12}$ Internalist accounts of justification may demand that $\mathrm{S}$ justifiably believes Value in order for (ii) to obtain.
} 
(Primary) Expressing the inference claim is a primary point made by the statement of an argument in arguing for its conclusion, not a secondary one.

Primary reflects a connection between a primary point in stating an argument and a primary aim in arguing for a conclusion. For example, if speaker S's primary aim in stating an argument in a critical discussion is to persuade the respondent of the conclusion, then the primary points conveyed by S's statement of an argument are what the addressee must accept in order to be persuaded by S's argument. The addressee must accept the inference claim in order to be so persuaded. Hence, Primary. Alternatively, one may take the primary aim of a complex act of argumentation to be showing that a target claim is correct. If so, then the primacy (the nonderivativeness) of expressing the inference claim is a consequence. That is, if a primary aim of S's in stating an argument in a critical discussion is to justify acceptance of the conclusion to the addressees, then expressing the corresponding inference claim is a primary point made by the statement of the argument.

\section{How is an inference claim expressed by the statement of an argument in arguing for its conclusion?}

A question previously posed is: what makes Pro's speech act of stating an argument count as a speech act of arguing for the conclusion? In response, Pro's speech act of stating an argument counts as a speech act of arguing for the conclusion only if the following three conditions obtain. First, Pro believes the corresponding inference claim. Second, the truth of Pro's statement suffices for the truth of the inference claim that is conveyed. Third, expressing the inference claim is a primary point of S's statement of the argument. More generally, the manner an inference claim is expressed by the statement of an argument in arguing for its conclusion satisfies Belief, Value, and Primary. For ease of reference, I repeat them so that they are in one place. 
(Belief) You express an inference claim by your statement of an argument in arguing for its conclusion only if you believe the inference claim.

(Value) If the statement of an argument made in arguing for its conclusion is true or acceptable, then so too is the inference claim it conveys.

(Primary) Expressing the inference claim is a primary point made by the statement of an argument in arguing for its conclusion, not a secondary one.

Appealing to these conditions, I now make the case that if a speaker $\mathrm{S}$ argues for a conclusion by stating an argument, then $\mathrm{S}$ thereby asserts the corresponding inference claim as opposed to merely implying it, conversationally implicating it, or conventionally implicating it. The case turns on the speech act of assertion fairing best in satisfying Belief, Value, and Primary out of these alternatives. The below scorecard summarizes the following discussion, "N" and "Y" abbreviate "No and "Yes," respectively.

Mere Implication

Conversational Implicature

Conventional Implicature

Assertion

$\begin{array}{cc}\text { (Belief) } & \text { (Value) } \\ \text { N } & \text { Y } \\ \text { N } & \text { N } \\ \text { N } & \text { N } \\ \text { Y } & \text { Y }\end{array}$

(Primary)

$\mathrm{Y}$

Y

$\mathrm{N}$

Y

As the table indicates, Belief alone establishes that if a speaker $\mathrm{S}$ argues for a conclusion by stating an argument, then $\mathrm{S}$ thereby asserts the corresponding inference claim. Value and Primary are worth discussing as a means of shedding further light on the status of inference claims. I now justify the entries, starting with mere implication.

\subsection{Mere Implication}

I label Mere implication as the position that an inference claim is merely implied by what is expressed in stating the corresponding 
argument in a critical discussion. Furthermore, I understand the notion of implication semantically. Accordingly, I take the position to hold that an inference claim is implied by virtue of the meaning of one or more expressions that occur in the statement of the argument.

For example, I take Hitchcock $(2007,2011)$ to hold that a speaker's statement of an argument in arguing for its conclusion implies the corresponding inference claim. His rationale is threefold. First, an inference claim, "can be marked linguistically by means of an illative expression (e.g., 'therefore,' 'since') governing the conclusion or reason" (2007, p. 106). Second, in order for a statement of an argument to express an inference claim, it must contain, explicitly or otherwise, an illative expression, which is in sync with Hitchcock's view that the components of arguments include illative expressions (2007, pp. 106-107). Third, the inference claim is an analytical implication of the meaning of the illative expression contained (perhaps, implicitly) in the statement of the argument. For example, "the word 'so' when used inferentially implies, as part of its meaning and not as some pragmatic implicature of its ordinary use, that the statement preceding it is relevant to the statement following it... in the sense that it helps to establish the truth of the conclusion" (2011, p. 214).

Mere implication moves beyond Hitchcock in being explicit that an inference claim is merely implied by the meaning of an illative expression that occurs, implicitly or otherwise, in what is expressed by the statement of an argument. If an inference claim may be conveyed by the statement of an argument even though an illative is not expressed, implicitly or otherwise, then this problematizes Mere implication. At any rate, Mere implication does not satisfy Belief, because implication is simply a relation between propositions that obtains regardless of a speaker's beliefs.

That is, the logical connection doesn't depend on your believing the implication. You say to me, "Beth is in the living room." "Beth is in the living room or in the kitchen" being an implication of the proposition you state doesn't depend on your believing the implication. Furthermore, on my view, belief is not closed under implication. Since what is implied by what you utter is independ- 
ent of whether or not you believe what is implied, implication fails Belief. ${ }^{13}$

Mere implication satisfies Value because, it preserves truth values. E.g., if $p$ implies $q$ and $p$ is true, then $q$ must be true. Also, Mere implication seems to satisfy Primary. Consider, he is either very smart or very silly, and he isn't very smart uttered in order to convey that he is very silly. This shows that you can intend the implication of what you express. In stating an argument, you may imply an inference claim in order to convey your belief of the inference claim. However, implication can't satisfy Belief this this way, because, again, believing the implication of what you express is not necessary for the implication to obtain.

\subsection{Conversational implicature ${ }^{14}$}

Does an arguer's statement of an argument in a critical discussion conversationally implicate the corresponding inference claim? An affirmative response is derivable from Bermejo-Luque's account (2011a, 2011b) of how inference claims are communicated when arguers argue for their conclusions by adducing premises in support of them. To illustrate, suppose that in the course of arguing for a claim $q$ in a critical discussion, Pro utters $p$ so $q$ in order to persuade Con that $q$ is true.

Following Bermejo-Luque (2011a, p. 64), Pro thereby implicitly asserts the material conditional, if $p$ then $q$, represented as $p \supset$ $q$. Bermejo-Luque thinks this is the inference claim (2011a, p.

\footnotetext{
${ }^{13}$ Of course, this doesn't rule out connections between the relation of implication and stating an argument. One might argue that stating an argument is undermined if you aren't prepared to at least defend the implications of that statement.

14 My discussion of conversational and conventional implicatures aims to present the elements of Grice's view of implicatures relevant to answering the question serving as section 4's title. Towards this end, I draw from Grice's 1967 publications "Logic and conversation" and "Further notes on logic and conversation." I rely on their reprints in Grice 1989. I also draw on the following sources that critically survey Grice's account of implicatures: well-known textbooks on linguistic communication (Levinson 1983, Bach and Harnish 1979); handbook and encyclopedia articles (Horn 2004, Korta and Perry 2020); review articles (Neale 1992, Potts 2007); and Bach's oft-cited critical discussions of Gricean implicatures in his 1994 and 1999 publications.
} 
62). ${ }^{15}$ Bermejo-Luque contends that Pro's intention to communicate that $q$ follows from $p$ is conveyed as a conversational implicature of Pro's implicit assertion that $p \supset q .{ }^{16}$ By virtue of believing that Pro abides by the Cooperative Principle and the conversational maxims guiding the critical discussion, Con is entitled to think that in asserting, $p \supset q$, Pro conveys as a conversational implicature that $q$ follows from $p$ (2011a, p. $64 ; 2011$ b, p. 335).

Conversational implicatures are essentially calculable. ${ }^{17}$ Borrowing from Bach and Harnish (1979, p. 169), Levinson (1983, 113-114), and Neale (1992, p. 527), I illustrate how Con's reasoning might run in calculating the conversational implicature, $q$ follows from $p$, of Pro's statement $p$ so $q$.

(1) Pro says $p$ so $q$ and thereby implicitly asserts $\mathrm{p} \supset \mathrm{q}$;

${ }^{15}$ Critics have pointed out that construing the content of inference claims in terms of the material conditional drains the normative force from them (e.g., Pinto 2011, et al). In response Bermejo-Luque's highlights the pragmatic aspect of the normative force of inference claims (2011a p. 175; 2011b, p. 335). For example, arguing that, Donald Trump likes asparagus, so $2<3$, is problematic (it's hardly imaginable!), because even though Donald Trump likes asparagus $\supset$ $2<3$ is true by virtue of the truth of its consequent, it is not appropriate, by Grice's Maxim of Quantity, to assert it solely on the basis of knowledge of the consequent. Hence, arguing as above is pragmatically flawed. However, Bermejo-Luque's response doesn't register why so arguing is epistemically flawed.

16 This requires that $p \supset q$ be part of what is said in stating the argument. The requirement is motivated by Grice's view that a conversational implicature is derived from what, if anything, is said by an utterance. On Grice's strict conception of what is said, what is said by an utterance must correspond to "elements of [the sentence uttered], their order, and their syntactic character" (1989, p. 87). Following others (e.g., Bach 1999, p. 335), this does not mean that what is said must be made fully explicit. For example, one can say that $p \supset q$ is communicated by a speaker's utterance, $p$ so $q$, by virtue of a correspondence between $p$ $\supset q$ and "so." This suffices for making $p \supset q$ implicitly asserted and so (implicitly) stated by the statement of the corresponding argument. A fuller account would spell out the nature of the correspondence between $p \supset q$ and the conclusion indicator.

17 "The presence of a conversational implicature must be capable of being worked out; for even if it can be intuitively grasped, unless the intuition is replaceable by an argument, the implicature (if present at all) will not count as a conversational implicature" (Grice 1989, p. 31). 
(2) There is no reason to suppose that Pro is not observing the conversational maxims and cooperative principle that guide the critical discussion;

(3) Only if Pro thinks that $q$ follows from $p$ is Pro's saying $p \supset q$ consistent with the presumption that Pro is observing the maxims and cooperative principle; ${ }^{18}$

(4) Pro knows (and knows that I know that Pro knows) that I can see that Pro thinks the supposition that Pro thinks that $q$ follows from $p$ is required;

(5) Pro has done nothing to stop me thinking that $q$ follows from $p$.

So, from (1)-(5), (6) Pro intends me to think, or is at least willing to allow me to think that $q$ follows from $p$.

So, from (6), (7) Pro has implicated that $q$ follows from $p$.

Steps 1-7 reflect three speech-act moves Pro makes in arguing for $q$ : (i) stating, $p$ so $q$, thereby (ii) (implicitly) asserting $p \supset q$, and (iii) conversationally implicating that $q$ follows from $p$. Con's reasoning, embodied in 1-7, reflects Con's belief that Pro's (implicit) assertion that $p \supset q$ is not sufficiently informative in the context of Pro's arguing for $q$. So, the conveyance of $q$ follows from $p$ requires Con's inference from the supposition that Pro wouldn't have said $p \supset q$ if Pro hadn't meant something more than that, i.e., hadn't also meant $q$ follows from $p$. I now make several comments that inform my evaluation of conversational implicature as the mechanism by which inference claims are expressed.

(a) Step 5 registers the cancelability of conversational implicatures (following Grice 1989, p. 44). This makes the pragmatic inferences that arise from such implicatures defeasible. In this way, they are more like inductive inferences than deductive ones (see Levinson

${ }^{18}$ That $q$ follows from $p$ is simply introduced at step (3) without explanation. One explanation is that in order to think that Pro's assertion that $p \supset q$ advances Pro's aim of stating $p$ so $q$, i.e., advances Pro's arguing for $q$, Pro should think that $q$ follows from $p$. 
1983, pp. 114-116). However, p so q, but q doesn't follow from $p$, seems problematic when the argument stated is an argument in its reason-giving sense. This suggests that the follows-from claim is either a part of what is said in uttering $p$ so $q$ used in a reason-giving way or is a conventional implicature of this utterance which isn't cancelable (as described below). Either way, this intuition counts against treating $q$ follows from $p$ as a conversational implication of $p \supset q$, assuming that $p \supset q$ is implicitly asserted in stating a reason-giving argument $p$ so $q$.

(b) Con's reasoning in calculating the implicature of Pro's assertion of $p \supset q$ is cogent even if Pro doesn't believe that $q$ follows from $p$. This is because failing to fulfill a maxim (or the Cooperative principle) may nevertheless give rise to implicatures. Following Bach and Harnish (1979, p. 167), one may quietly and unostentatiously fail to fulfill a maxim, which is likely to mislead. In such a case, Pro's assertion that $p \supset q$ is infelicitous, precisely because it implicates that $q$ follows from $p$ which Pro does not believe.

(c) Since an implicature is not part of what is said by the utterance from which the implicature is inferred, it may be neither true nor acceptable while what is said is true or acceptable. E.g., $p \supset q$, may be true even though $q$ does not follow from $p$. Not satisfying Value, distinguishes implicatures (both conventional and conversational) from implication.

Conversational implicature does not satisfy Belief. Suppose that Pro states an argument, $p$ so $q$, and thereby conversationally implicates that $q$ follows from $p$. Conversational implicature satisfies Belief only if it is necessary that Pro believe that $q$ follows from $p$ in order for Pro to implicate this. Given point (b) above, this isn't the case. Hence, conversational implicature fails Belief. Certainly, Pro saying $p \supset q$ as part of stating the argument while not believing that $q$ follows from $p$ is infelicitous since Pro is on the hook for defending if not believing that $q$ follows from $p$. However, this is 
insufficient for conversational implicature satisfying Belief. Assuming responsibility for believing the follows-from claim is short of believing it. Supposing that Pro doesn't believe that $q$ follows from $p$, it is nevertheless expressed as an implicature of Pro's utterance since Pro did not explicitly opt out of following the maxims (or cooperative principle).

Given point (c), conversational implicature doesn't satisfy Val$u$. For example, what you utter may be true even though what you implicate by your utterance is false. However, conversational implicature satisfies Primary. Consider an utterance, I am on a diet, made in response to the following question. Would you like dessert? Plausibly, a primary aim of the speaker's utterance is to convey as a conversational implicature that the speaker does not want dessert.

\subsection{Conventional implicature}

According to Grice (1989), the statement of an argument that explicitly uses an illative expression (e.g., "since," "therefore") conventionally implicates the corresponding inference claim. ${ }^{19}$ Bach defines conventional implicature as follows.

A proposition is a conventional implicature of an utterance just in case (a) the speaker (speaking seriously) is committed to the truth

${ }^{19}$ In an oft-cited passage, Grice introduces the notion of conventional implicatures in his well-known "Logic and Conversation" in order to distinguish them from conversational implicatures which is his main concern:

In some cases the conventional meaning of the words used will determine what is implicated, besides helping to determine what is said. If I say (smugly), He is an Englishman; he is, therefore, brave, I have certainly committed myself, by virtue of the meaning of my words, to its being the case that his being brave is a consequence of (follows from) his being an Englishmen. But while I have said that he is an Englishman, and said that he is brave, I do not want to say that I have said (in the favored sense) that it follows from his being an Englishman that he is brave, though I have certainly indicated, and so implicated, that this is so. I do not want to say my utterance of this sentence would be, strictly speaking, false should the consequence in question fail to hold. So some implicatures are conventional, unlike the one [a conversational implicature] which I introduced this discussion of implicature. (1989, pp.25-26) 
of the proposition, (b) which proposition that is depends upon the (or a) conventional meaning of some particular linguistic device in the utterance, but (c) the falsity of that proposition is compatible with the truth of the utterance. $(1999$, p. 331)

Condition (b) grounds the fact that conventional implicatures are not cancelable. Horn puts this as, "[they are] not CANCELABLE without contradiction" $(2004$, p. 4). This accommodates the intuition that there is something always wrong in uttering $p$ so $q$, but $q$ doesn't follow from $p$, when the argument is being used in a reason-giving way. Also, an illative has to occur in what is uttered in order for the corresponding inference claim to be conventionally implicated. So, if statements of arguments convey inference claims as conventional implicatures, then they must contain, explicitly or otherwise, an illative expression.

The expressions "therefore" and "but" are often used to illustrate conventional implicatures (but see Bach 1999, discussed below). Suppose (i) and (ii) are uttered in ordinary conversations.

(i) Beth is listening to music, but she is in the living room.

(ii) Beth is listening to music; therefore, she is in the living room.

The descriptive meaning of utterances (i) and (ii), what Grice identifies with what is said, is the same: (iii) Beth is listening to music and she is in the living room. If either conjunct in (iii) is false, then so are (i) and (ii). Sample conventional implicatures of utterances (i) and (ii) are: $\mathrm{CI}_{\mathrm{i}}-$ Beth is not usually listening to music in the living room; $\mathrm{CI}_{\mathrm{ii}}-$ Beth is in the living room follows from Beth is listening to music. The CIs illustrate conventional meanings of utterance (i) and (ii) in typical conversational settings.

Pro utters $p$, so $q$ in a critical discussion. Treating the inference claim, $q$ follows from $p$, as an implicature of Pro's utterance takes it to be a meaning of the utterance that is not part of what Pro says. Accordingly, in stating $p$, so $q$, Pro is not saying $q$ follows from $p$. If the inference claim is a conversational implicature of Pro's utterance, then it is a pragmatic meaning that arises from the interaction between the communicative goals of Pro and Con in their 
critical discussion, and the conversational maxims guiding rational communication. In contrast, if $q$ follows from $p$ is a conventional implicature of Pro's utterance, $p$ so $q$, then it is a conventional meaning of Pro's utterance that stems entirely from the conventional meaning of "so." However, the meaning of "so" does not contribute to what Pro says and so does not affect the truth or falsity of what Pro says. ${ }^{20}$

Conventional implicature does not satisfy Belief, because conventional implicature stems entirely from the conventional meanings of lexical items or grammatical constructions occurring in the sentence uttered. If my utterance of $p$ so, $q$ conventionally implicates that $q$ follows from $p$, then it does so regardless of whether or not I believe my commitment to the inference claim. Therefore, conventional implicature fails Belief.

According to Grice, the meaning of a conventional implicature does not contribute to the truth-conditional content of the statement that has the conventional implicature. Accordingly, conventional implicature does not satisfy Value, since, like conversational implicature, it does not necessarily preserve acceptability or truth. For example, what is uttered may be true even though what is conventionally implicated by the utterance is false. The oddity of treating the value of the inference claim as irrelevant to the value of the argument's statement can be brought out by considering a clearly invalid argument with true premisses and a true conclusion, such as the argument: "Some politicians are men and some politicians are corrupt, so some men are corrupt." Would it be coherent to say: "That's true, but your conclusion doesn't actually follow from the reasons you give"? If the correct response is affirmative, then Grice's position is vindicated. If the correct response is negative as I think, then Grice's position is refuted.

\footnotetext{
${ }^{20}$ As is commonly noted (e.g., see Korta and Perry 2020), an internal tension in Grice's view of conventional implicatures results from Grice maintaining that (i) a conventional implicature is a conventional meaning of an utterance, (ii) the conventional meaning of an utterance contributes to the truth-conditional content of what is said, and (iii) the meaning of a conventional implicature does not contribute to the truth-conditional content of the corresponding utterance. Claims (i)-(iii) are prima facie incompatible.
} 
Moving to Primary, it is standard to think that the proposition expressed by a conventional implicature is secondary to the main assertion of a declarative sentence (e.g., see Abbott 2011, Potts 2007). Following Potts (2007, p. 667), at the discourse level we find if one objects to an assertion of, say, (i) on the previous page, one is not construed as having objected to $\mathrm{CI}_{i}$ which is liable to slip quietly to the common ground, unless the objector is explicit that she objects to the $\mathrm{CI}_{\mathrm{i}}$-content as well. This illustrates what Potts calls the assertoric inertness of conventional implicatures (2007, p. 672). That conversational implicatures are assertorically inert is a reason to think that they do not satisfy Primary.

Before turning to assertion, it is worth considering Bach (1999, pp. 338-343) who argues that conventional implicatures do not exist. Obviously, if this is correct then this counts against construing an arguer's inference claim as a conventional implicature of the statement of the argument. Bach deploys what he calls the IQtest (the indirect quotation test) to make the case that conventional implicatures are not distinguished from the descriptive meaning of utterances and so are part of what is said in the sense of Grice. To illustrate, between (ii) and (iii), which is an accurate paraphrase, using indirect quotation, of what $\mathrm{S}$ uttered?

$\mathrm{S}$ : (i) Beth is listening to music on the stereo and therefore Beth is in the living room

(ii) S said that Beth is listening to music on the stereo and therefore Beth is in the living room.

(iii) S said that Beth said that Beth is listening to music on the stereo and that Beth is in the living room.

According to Bach, it's (ii). Statement (iii) leaves out the contribution of "therefore"; unlike (ii), it does not report S's statement of an argument. If (ii) is true, which seems right, then what $\mathrm{S}$ says is (i). If S had just said that Beth is listening to music on the stereo and that Beth is in the living room, then (ii) would be partly untrue. 


\subsection{Assertion}

As some have noted (e.g., Bach 1999, p. 330), Grice's example of "therefore" as a device of conventional implicature is unfortunate since that $q$ follows from $p$ seems to be required for the truth of what is stated by uttering $p$, therefore $q$. This suggest that, contra Grice, $q$ follows from $p$ is part of what is said in stating $p$, therefore $q$. Hitchcock remarks that in stating an argument-in its reason-giving sense- - " $\mathrm{t}]$ he arguer implicitly claims [italics are his] that the conclusion... follows from the reason or reasons from which it is drawn" (2011, pp. 191-192). Accordingly, by stating an argument in its reasoning giving sense a speaker claims, i.e., asserts, the corresponding inference claim.

What distinguishes assertion from other types of speech acts? ${ }^{21}$ I favor an expressive account of assertion (for challenges see MacFarlane 2011). Briefly, your utterance counts as an assertion only if it expresses your belief of the propositions stated (Searle 1979 p. 12, Bach and Harnish 1979 p. 42). Expression of belief are caused by the beliefs they express (Williams 2002, pp. 73-75, Owens 2006). As noted by Williams (2002, p. 74), since only sincere assertions can express beliefs in this direct way, insincere assertions are assertions in a parasitic sense. ${ }^{22}$ Since you express an inference claim by means of sincerely asserting it only if you believe it, (sincere) assertion satisfies Belief.

Assertion satisfies Value. In arguing for a conclusion by stating an argument, a speaker S performs the speech acts of asserting the premises, the conclusion, and asserting the corresponding inference claim. Drawing on Bach (1999), Potts labels the phenomenon of an individual sentence that is uttered expressing multiple mean-

\footnotetext{
${ }^{21}$ For useful overviews of the many different accounts of assertion developed in response, see Brown and Cappelen (2011b) and Pagin (2016).

${ }^{22}$ According to Williams, "....the standard conditions of A's asserting that $\mathrm{P}$ are that A utters a sentence ' $S$,' where ' $S$ ' means that $P$, in doing which either he expresses his belief that $\mathrm{P}$, or he intends the person addressed to take it that he believes that P" (2002, p.74). The second disjunct, which accommodates acts of insincere assertion, expresses what I take to be the sincerity condition for A's act of conversationally implicating that P by uttering "S." Again, as previously suggested, A conversationally implicating that $\mathrm{P}$ does not require that A believe P.
} 
ings, semantic multidimensionality (2007, pp. 674-676). Construing the meaning of a sentence as the proposition it expresses, semantic multidimensionality is instantiated by a one-sentencepotentially-many-propositions semantics. This enables the analysis of the meaning of a speaker S's utterance, $p$, so $q$ in terms of two propositions expressed by the sentence $\mathrm{S}$ utters: $p$ and $q$, $q$ follows from $p$. Here, what is expressed comprises more than one proposition. Since part of what is expressed in stating an argument is the inference claim asserted, the inference claim must be true if what is stated in the statement of the argument is true. Finally, assertion accommodates Primary by the fact that the inference claim is asserted, and what is asserted in an utterance is a primary point of the utterance.

In sum, S's assertion $p$, so $q$ by means of uttering it asserts that $q$ follows from $p$, which is among the propositions expressed by S's utterance. Since S doesn't utter $q$ follows from $p$, the question arises what determines whether the assertion of the inference claim by means of uttering $p$, so $q$ is implicit or explicit. Here I follow Grice in understanding what is explicitly expressed by an utterance strictly in terms of what is said by means of the utterance (see note 16 , above). Defense of this substantive claim is beyond the scope of this paper. Briefly, by stating an argument you explicitly assert the corresponding inference claim only if you utter an illative expression in stating the argument. Otherwise, the inference claim is implicitly asserted. ${ }^{23}$

I've said that statements of arguments in their reason-giving sense are truth-evaluable. However, as Bach notes (1999, p. 354), a sentence that expresses more than one proposition, rather than a conjunction of them, does not have a unitary truth condition. If my utterance expresses several propositions all true except for one, is what I say false? Without addressing this question directly, we can say that what is uttered by stating an argument is true if every proposition that is expressed is true.

${ }^{23}$ I distinguish between implicit assertions and mere implications. Taking $\mathrm{S}$ to be implicitly asserting an inference claim construed as a mere implication of her statement of the argument threatens to erase what many take to be an intuitive and useful distinction between what is asserted and what is merely implied (e.g., McFarlane 2011, p. 80). 
That assertion satisfies Belief, Value, and Primary provides a rationale for the paper's central thesis: by stating an argument in arguing for its conclusion in its core sense a speaker $\mathrm{S}$ asserts the associated inference claim. Before concluding, I now sketch my responses to two objections to this thesis.

One form of pushback questions the belief condition, which I have labelled Belief. This criticism says that when one argues for a conclusion one necessarily represents oneself as believing that the conclusion follows from the premises given in its support. Of course, merely representing oneself as believing $p$ isn't to believe $p$. My initial response is two-fold. First, the criticism presupposes that there is just one way of arguing for a conclusion, which I reject. Again, my focus here is on arguing for a conclusion by advancing an a persona argument. Surely, this is one way people, in fact, argue. I take this to be arguing for a conclusion in its core sense. Second, when one presents an a persona argument one advances the premises as one's reasons for which one believes the conclusion. One doesn't advance the premises so construed unless one believes that the conclusion follows from them. I defend this substantive claim in forthcoming work. A takeaway here is that how we understand what counts as arguing for a conclusion matters to how we think the inference claim is conveyed by one's statement of the corresponding argument.

Another form of pushback undercuts motivation for the paper's central thesis by advancing either an alternative plausible story about mere implication or a Neo-Gricean account of implicature that satisfies Belief, Value, and Primary. For example, regarding mere implication, one might follow Harman (1986) and argue that one believes what is easily inferable from what one expresses. Harman distinguishes between explicit and implicit belief. Briefly, you believe something explicitly if your belief involves an explicit mental representation whose content is the content of that belief (p. 13). You believe something only implicitly if it is not explicitly believed, but, for example, is easily inferable from one's explicit beliefs (p. 13). Given that you explicitly believe that Beth has at most four children, one can easily infer that Beth does not have five children, that Beth does not have six, and so on. So, all these 
propositions are things that Beth believes implicitly. ${ }^{24}$ In response, I say that one doesn't argue for a conclusion by advancing one's reasons for it (i.e., doesn't advance an a persona argument) unless one explicitly believes the associated inference claim, i.e., unless one possesses, in a belief-like way, a representation with that content. Development of this response is beyond the scope of this paper.

\section{Conclusion}

One way of arguing for a conclusion is by stating an argument for it. How must the associated inference claim be conveyed? Answers depend on the operative sense of arguing for a conclusion. Here I have focused on arguing for a conclusion in what I think is its core sense. Arguing for a conclusion in this way involves advancing an a persona argument, i.e., an argument put forward as the author's own for the conclusion. I've motivated the conditions Belief, Value and Primary by considering the connection between arguing for a conclusion so construed and inference claims. Of the alternatives considered here, I have argued that assertion best satisfies Belief, Value and Primary as opposed to mere implication and implicature. Accordingly, when stating an argument in order to argue for its conclusion - in its core sense-one asserts the corresponding inference claim as opposed to merely implying or implicating it.

\section{Acknowledgements}

Thanks to the reviewer whose substantive and insightful comments on an earlier draft greatly improved the paper. Also, thanks to Michael O'Rourke for his comments on an earlier draft and thanks to David Godden for discussions that helped my thinking on several topics addressed in the paper. Of course, I am solely responsible for any remaining errors.

\footnotetext{
${ }^{24}$ For other ways that something can be merely implicitly believed see Harman 1986, pp. 13-14.
} 


\section{References}

Abbott, Barbara. 2006. Where have some of the presuppositions gone? In Drawing the boundaries of meaning: Neo-Gricean studies in pragmatics and semantics in honor of Laurence R. Horn, eds. B. Birner and G. Ward, 1-20. Philadelphia: John Benjamins.

Aikin, Scott and Robert Talisse. 2019. Why we argue (and how we should). New York: Routledge.

Bach, Kent. 1994. Conversational impliciture. Mind and Language 9: 124-162.

Bach, Kent. 1999. The myth of conventional implicature. Linguistics and Philosophy 22: 262-283.

Bach, Kent and Robert Harnish. 1979. Linguistic communication and speech acts. Cambridge, MA: MIT Press.

Bermejo-Luque, Lilian. 2011a. Giving reasons: a linguistic-pragmatic approach to argumentation theory. Dordrecht: Springer.

Bermejo-Luque, Lilian. 2011b. Exchanging reasons: Responses to critics. Theoria 72: 329-334.

Biro, John and Harvey Siegel. 2006. In defense of the objective epistemic approach to argumentation. Informal Logic 26: 91-101.

Brown, Jessica and Herman Cappelen. 2011a. Assertion: New philosophical essays. New York: Oxford UP.

Brown, Jessica and Herman Cappelen. 2011b. Assertion: An introduction and overview." In Assertion: New philosophical essays, 1-17.

Copi, Irving and Carl Cohen. 2005. Introduction to logic, $12^{\text {th }}$ ed. Upper Saddle River, NJ: Pearson/Prentice Hall.

Corcoran, John (ed.). 1993. Editor's introduction. In An introduction to logic, $2^{\text {nd }}$, ed. Morris Cohen and Ernest Nagel, pp. xvii-xlvi. Indianapolis: Hackett Pub. Co.

Eemeren F. H. van and R. Grootendorst. 1984. Speech acts in argumentative discussions: A theoretical model for the analysis of discussions directed towards solving conflicts of opinion. Berlin/Dordrecht: De Gruyter/Foris Publications.

Eemeren F. H. van and R. Grootendorst. 2004. A systematic theory of argumentation: The pragma-dialectical approach. New York: Cambridge UP.

Eemeren F. H. van and P. Houtlosser. 2003. The development of the pragma-dialectical approach to argumentation. Argumentation 17: 387-403.

Epstein, Richard. 2002. Five ways of saying "therefore." Belmont, CA: Wadsworth/Thompson Learning. 
Goldman, Alvin. 1994. Argumentation and social epistemology. Journal of Philosophy 91: 27-49.

Govier, Trudy. 2010. A practical study of argument, $7^{\text {th }}$ ed. Belmont, CA: Wadsworth Cengage Learning.

Grennan, Walter. 1994. Are 'gap-fillers' missing premises? Informal Logic 16: 185-196.

Grice, H. P. 1989. Studies in the way of words. Cambridge, MA: Harvard UP.

Groarke, Leo. 2002. Hilary Putnam on the end(s) of argument. Philosophica 69: 41-60.

Hamblin, C.L. 1970. Fallacies. London: Methuen \& Co Ltd.

Hitchcock, David. 2007. Informal logic and the concept of argument. In Philosophy of Logic, ed Dale Jacquette, 101-129. Amsterdam: Elsevier.

Hitchcock, David. 2011. Inference claims. Informal Logic 31: 191-228.

Horn, Larry. 2004. Implicature. In The handbook of pragmatics, eds L.R. Horn and G. Ward, 3-28. Malden, MA: Blackwell Publishing Ltd.

Kelley, David. 2014. The art of reasoning: An introduction to logic and critical thinking, $4^{\text {th }}$ ed. New York: W.W. Norton \& Company, Inc.

Korta, Kepa and John Perry. 2020. Pragmatics. In The Stanford encyclopedia of philosophy (Spring Edition), ed. Edward N. Zalta. URL accessed 16 July 2020:

$<$ https://plato.stanford.edu/archives/spr2020/entries/pragmatics/>.

Levinson, Stephen.1983. Pragmatics. Cambridge: Cambridge UP.

MacFarlane, John. 2011. What is assertion? In Assertion: New philosophical essays, 79-96.

Meiland, Jack. 1989. Argument as inquiry and argument as persuasion. Argumentation 3: 185-196.

Neale, Stephen. 1992. Paul Grice and the philosophy of language. Linguistics and Philosophy 15: 509-599.

Owens, David. 2006. Testimony and assertion. Philosophical Studies 130: 105-129.

Pagin, Peter. 2016. Assertion. In The Stanford encyclopedia of philosophy (Winter Edition), ed. Edward N. Zalta. URL accessed 13 August 2020:

$<$ https://plato.stanford.edu/archives/win2016/entries/assertion/>.

Pinto, Robert. 2001. The relation of argument to inference. In Argument, inference, and dialectic, ed. R. Pinto, 32-45. Dordrecht: Kluwer Academic Pub.

Pinto, Robert. 2011. The account of warrants in Bermejo-Luque's giving reasons." Theoria 72: 311-320. 
Potts, Christopher. 2007. Into the conventional-implicature dimension. Philosophy Compass 2: 665-679.

Scriven, Michael. 1976. Reasoning. New York: McGraw-Hill Book Co.

Searle, John. 1969. Speech acts: An essay in the philosophy of language. Cambridge: Cambridge UP.

Searle, John. 1979. Expression and meaning: Studies in the theory of speech acts. Cambridge: Cambridge UP.

Sinnott-Armstrong, Walter and Robert Fogelin. 2010. Understanding arguments. Belmont, CA: Wadsworth Cengage Learning.

Thomson, Judith Jarvis. 1967. Reasons and reasoning. In Philosophy in America, ed Max Black, 282 - 303. Ithaca, NY: Cornell UP.

Vorobej, Mark. 2006. A theory of argument. Cambridge: Cambridge UP.

Williams, Bernard. 2002. Truth and truthfulness. Princeton: Princeton UP. 